УДК 634.11:631.524.82

DOI 10.30679/2219-5335-2021-3-69-170-182

ОСОБЕННОСТИ РЕАЛИЗАЦИИ ПРОДУКЦИОННОГО ПРОЦЕССА В ВЫСОКОПЛОТНЫХ НАСАЖДЕНИЯХ ЯБЛОНИ*

Чумаков Сергей Семенович

д-р с.-х. наук, профессор

кафедры плодоводства

Беляева Анастасия Валерьевна аспирант

Федеральное государственное бюджетное образовательное учреждение высшего образования «Кубанский государственный аграрный университет имени И.Т. Трубилина», Краснодар, Россия

Изучено влияние схем размещения на особенности реализации продукционного процесса растений яблони сортов Ренет Симиренко, Голден Делишес Рейнджерс, Кубанское багряное, Гала, Фуджи, привитых на карликовом подвое М9. Эксперименты проведены в 2016-2019 гг. в высокоплотных насаждениях яблони 2016 года посадки с использованием интенсивной технологии возделывания в условиях учхоза «Кубань» прикубанской зоны садоводства. В опыте изучали три схемы размещения: $4,0 \times 1,5 \mathrm{M}$ (контроль), 4,0 × 1,0 м, 4,0 × 0,5 м. Наступление периода товарного плодоношения яблоневых насаждений отмечено на третий год после закладки сада. Установлено, что при уплотнении посадок активизировалась закладка генеративных почек. Наибольшее количество полезных завязей у растений яблони всех изучаемых сортов было сформировано при контрольной схеме посадки 4,0 × 1,5 м, что положительно отразилось на формировании хозяйственного урожая (кг/дер.).
UDC 634.11:631.524.82

DOI 10.30679/2219-5335-2021-3-69-170-182

\section{PECULIARITIES \\ OF THE PRODUCTION PROCESS IN HIGH-DENSITY APPLE PLANTATIONS*}

Chumakov Sergey Semenovich

Dr. Sci. Agr., Professor

of the Horticulture Department

Belyaeva Anastasia Valerievna postgraduate student

Federal State

Budgetary Educational

Institution of Higher Education

«Kuban State Agrarian University

named after I.T. Trubilin»,

Krasnodar, Russia

The influence of layout schemes

on the peculiarities of the production

process of apple plants of the varieties

Renet Simirenko, Golden Delicious Rangers,

Kubanskoe bagryanoe, Gala and Fuji grafted on a dwarf rootstock M9 was studied.

The experiments were carried out in 2016-2019 in high-density plantations of apple trees planted in 2016 with application of intensive cultivation technology under the conditions of the Kuban educational farm «Kuban» in the Kuban horticultural zone. Three layout schemes were studied in the experiment: $4,0 \times 1,5 \mathrm{~m}$ (control), 4,0 × 1,0 m, 4,0 × 0,5 m. Start of the period of marketable fruiting of apple plantations was noted in the third year after the garden was laid. It was found that when the plantings were compacted, the formation of generative buds was activated. The greatest number of useful ovaries in apple plants of all studied varieties was formed with the control layout scheme $4.0 \times 1.5 \mathrm{~m}$, which affected the productivity of plants - the highest yield ( $\mathrm{kg} /$ tree) .

The difference with the experimental

\footnotetext{
* Исследование выполнено при поддержке РФФИ и Администрации Краснодарского края (проект № 19-44230013 p_a)

* The research was carried out with supported of the Russian Foundation for Basic Research and the Administration of the Krasnodar Territory (Grant No. 19-44230013 r_a)
} 
Разница с опытными вариантами составила 11,2-51,2\% (при схеме посадки 4,0 × 0,5 м); до 13,4 \% (при схеме посадки $4,0 \times 1,0$ м). Однако, в условиях максимального уплотнения $(4,0 \times 0,5$ м) урожайность растений (т/га) была выше на 27,2-140,0 \%, в сравнении с контрольным вариантом опыта. При схеме размещения деревьев $4,0 \times 1,0$ м разница с контролем составила $25,0-85,0 \%$. Отмечено, что уплотнение насаждений не оказало существенного влияния на товарное качество плодов средняя масса плодов (150-246 г) не уменьшалась или уменьшалась незначительно относительно контроля; также не отмечено влияния схем размещения на содержание сахара в плодах растений яблони.

Ключевые слова: ЯБЛОНЯ, СХЕМЫ РАЗМЕЩЕНИЯ, ИНТЕНСИФИКАЦИЯ САДОВОДСТВА, ПРОДУКТИВНОСТЬ, КАЧЕСТВО variants was $11,2-51,2 \%$ (with a layout scheme of $4,0 \times 0,5 \mathrm{~m}$ ); up to $13,4 \%$ (with a layout scheme of 4,0 $\times 1,0 \mathrm{~m}$ ). However, under conditions of maximum compaction $(4,0 \times 0,5 \mathrm{~m})$, the yield of plants ( $\mathrm{t} / \mathrm{ha}$ ) was higher by $27,2-140,0 \%$ in comparison with the control variant of the experiment. With the layout scheme of $4,0 \times 1,0 \mathrm{~m}$, the difference with the control was $25,0-85,0 \%$. It was noted that the compaction of plantations did not have a significant effect on the commercial quality of fruits the average weight of fruits (150-246 g) did not decrease or decreased slightly relative to the control; also, no influence of the planting schemes on the sugar content in the fruits of apple plants was noted.

Key words: APPLE TREE, LAYOUT

SCHEMES, GARDENING

INTENSIFICATION, PRODUCTIVITY, QUALITY

Введение. В настоящее время основной задачей отрасли садоводства является наиболее полная реализация продукционного потенциала плодовых растений [1]. Увеличение продуктивности деревьев яблони происходит за счет принятия различных мер, прямо и косвенно влияющих на интенсивность физиологических процессов плодовых деревьев [2, 3]. Одним из направлений увеличения продуктивности плодовых насаждений является разработка и внедрение в производство рациональных и эффективных типов насаждений, как с биологической, так и с экономической точек зрения. Так, современные коммерческие яблоневые сады в основном закладываются с использованием интенсивной технологии возделывания, которая обеспечивает более раннее вступление деревьев в пору товарного плодоношения, получение высококачественных плодов, стабильную урожайность в течение всего периода их эксплуатации и, как следствие, высокую рентабельность производства [4-13].

При проектировании высокоплотных насаждений яблони, в частности, определении площади питания растений, в целях более полной реали- 
зации хозяйственного потенциала необходимо учитывать ростовую активность используемого сортимента. Выбор оптимального расстояния между плодовыми деревьями обеспечивает эффективное использование трудовых и земельных ресурсов, хорошее освещение кроны, физиологический баланс между ростом и плодоношением для более раннего вступления деревьев в период товарного плодоношения, достижения наибольшей урожайности и высокого товарного качества плодов [14-18]. Также существует проблема недостаточной информированности производителей о «поведении» сортимента при высокой плотности посадки в конкретных условиях каждого региона выращивания. В связи с этим, целью данной работы являлась оценка влияния различных схем размещения растений яблони на реализацию продукционного процесса в условиях прикубанской зоны садоводства.

Объекты и методы исследований. Исследования проводили в 2016-2019 гг. в высокоплотных насаждениях яблони 2016 года посадки с использованием интенсивной технологии возделывания в условиях учхоза «Кубань» (Кубанский ГАУ) прикубанской зоны садоводства.

Объектами исследований являлись следующие сорта яблони: Ренет Симиренко, Голден Рейнджерс, Кубанское багряное, Гала, Фуджи, широко распространённые в коммерческих садах прикубанской зоны садоводства и привитые на карликовом подвое М9. Варианты опытов предусматривали использование следующих схем размещения: 4,0 × 1,5 м (контроль), 4,0 × 1,0 м, 4,0 $\times$ 0,5 м. Повторность вариантов шестикратная. Размер делянки - дерево делянка. Учеты и наблюдения проводили согласно общепринятым программам и методикам [19]. Оценивали степень дифференциации плодовых почек, количество цветков (шт./дер.), полезной завязи (шт./дер.), плодов (шт./дер.), качество плодов, продуктивность (кг/дер.; т/га). Приготовление временных анатомических препаратов плодовых почек для микроскопирования осуществляли по методике Г.К. Киселевой [20]. 
Обсуждение результатов. Плотность посадки растений является базовым фактором в совершенствовании структуры сада, как оптико-фотосинтезирующей системы [21]. Растения в плотных посадках полнее используют площадь, отводимую под одно растение, минеральное питание и воду, в связи с чем повышаются темпы роста и развития растений, особенно в первые годы плодоношения. В садах с высокой плотностью размещения растений отмечается более активное формирование листовой поверхности, а также рациональное использование ФАР. Интенсивность солнечной радиации, в свою очередь, влияет на процессы фотосинтеза и распределения ассимилятов, на закладку цветковых почек, рост и качество плодов [21].

Так, установлено, что уплотненное размещение деревьев оказало положительное влияние на процессы закладки и дифференциации генеративных почек у растений яблони всех изучаемых сортов. В частности, у растений яблони сорта Голден Делишес Рейнджерс в варианте со схемой размещения 4,0 × 0,5 м начало 3-го этапа органогенеза генеративных почек [22, 23] (на примере кольчаток) отмечалось на 10-14 дней раньше, чем в других вариантах опыта (рис. 1). Данная тенденция развития генеративных почек сохраняется и в дальнейшем.

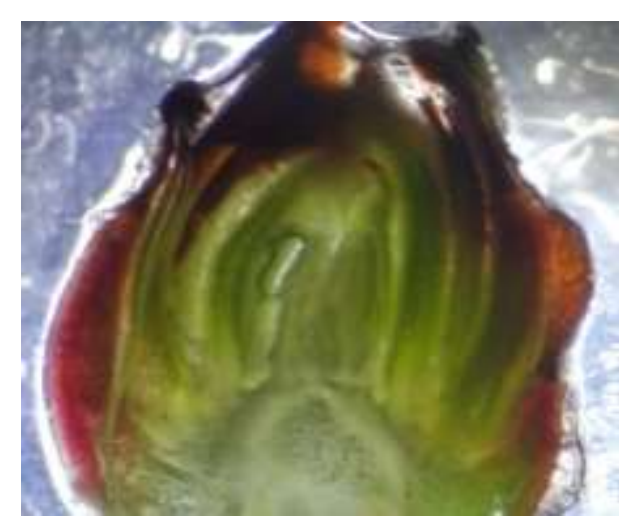

a)

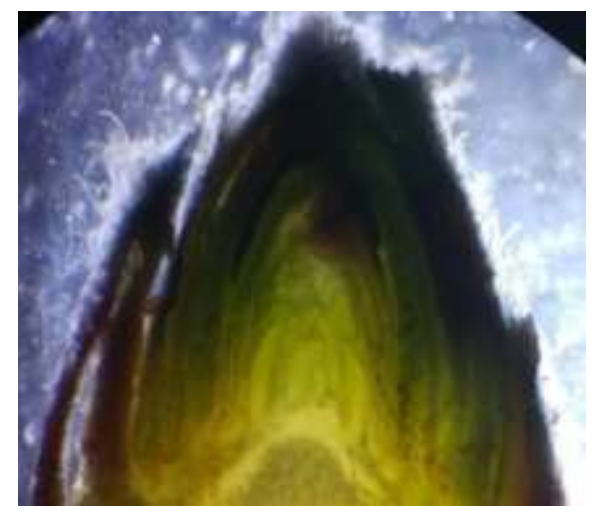

б)

Рис. 1. Влияние схем размещения растений на особенности дифференциации генеративных почек (кольчаток) яблони (на примере сорта Голден Делишес Рейнджерс) (2 декада июля 2018 г.) при схемах посадки: а) - 4,0 × 0,5 м; б) - 4,0 × 1,5 м 
Показатель закладки генеративных почек также достигал максимальных значений в варианте со схемой посадки 4,0 × 0,5 м и превышал другие варианты опыта на 12,0 и 25,0 \% соответственно (рис. 2).

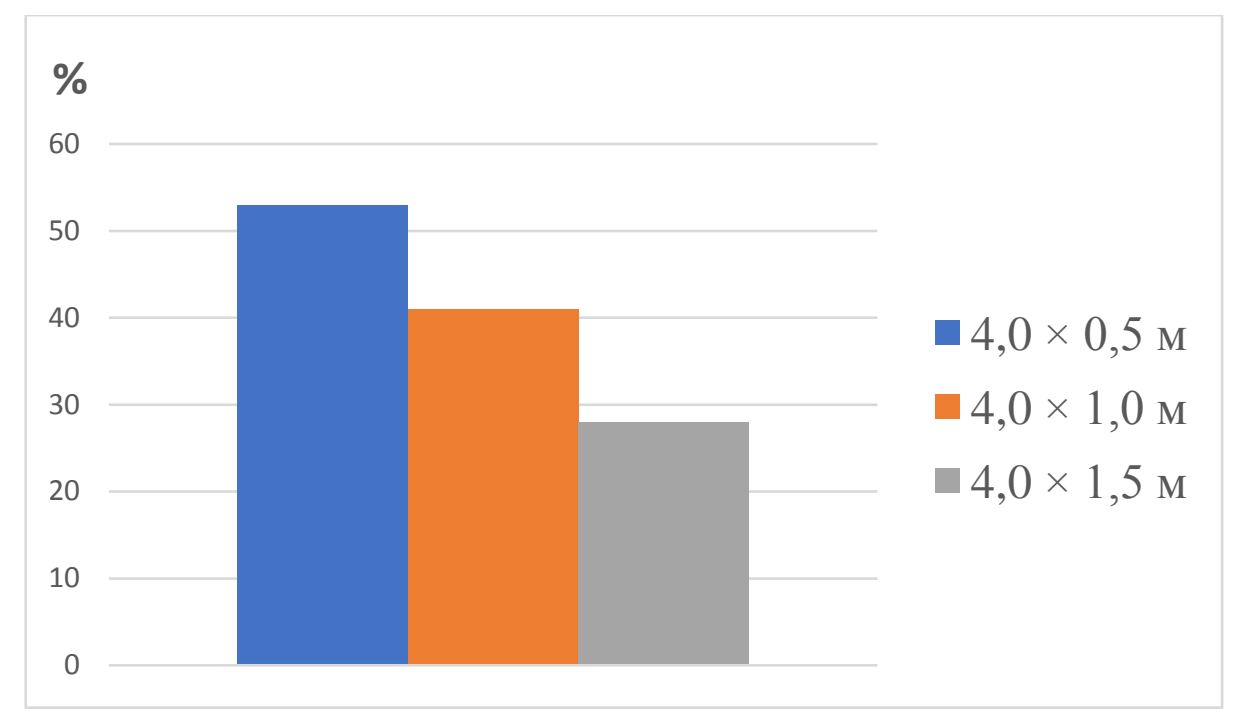

Рис. 2. Влияние схем размещения растений на закладку генеративных почек (кольчаток) яблони (на примере сорта Голден Делишес Рейнджерс) (2 декада июля 2018 г.)

В процессе экспериментов определено, что схема размещения растений оказывает значимое влияние на реализацию генеративной функции растений яблони уже в первый год товарного плодоношения (рис. 3).

Определено, что наибольшее количество полезной завязи у растений яблони всех изучаемых сортов было сформировано в контрольном варианте - при более разреженной схеме размещения деревьев. Разница с опытными вариантами составила: при схеме посадки 4,0 × 0,5 м - 11,2-51,2 \%, при схеме посадки 4,0 × 1,0 м - до 13,4\%.

В процентном отношении образование полезной завязи и сформировавшихся плодов зависело не только от плотности посадки, но и от сортовой специфики. В частности, максимальная доля полезной завязи от количества цветков у растений сорта Ренет Симиренко отмечена при схеме посадки 4,0 × 1,0 м - на 5,6 \% больше, чем в контрольном варианте. 


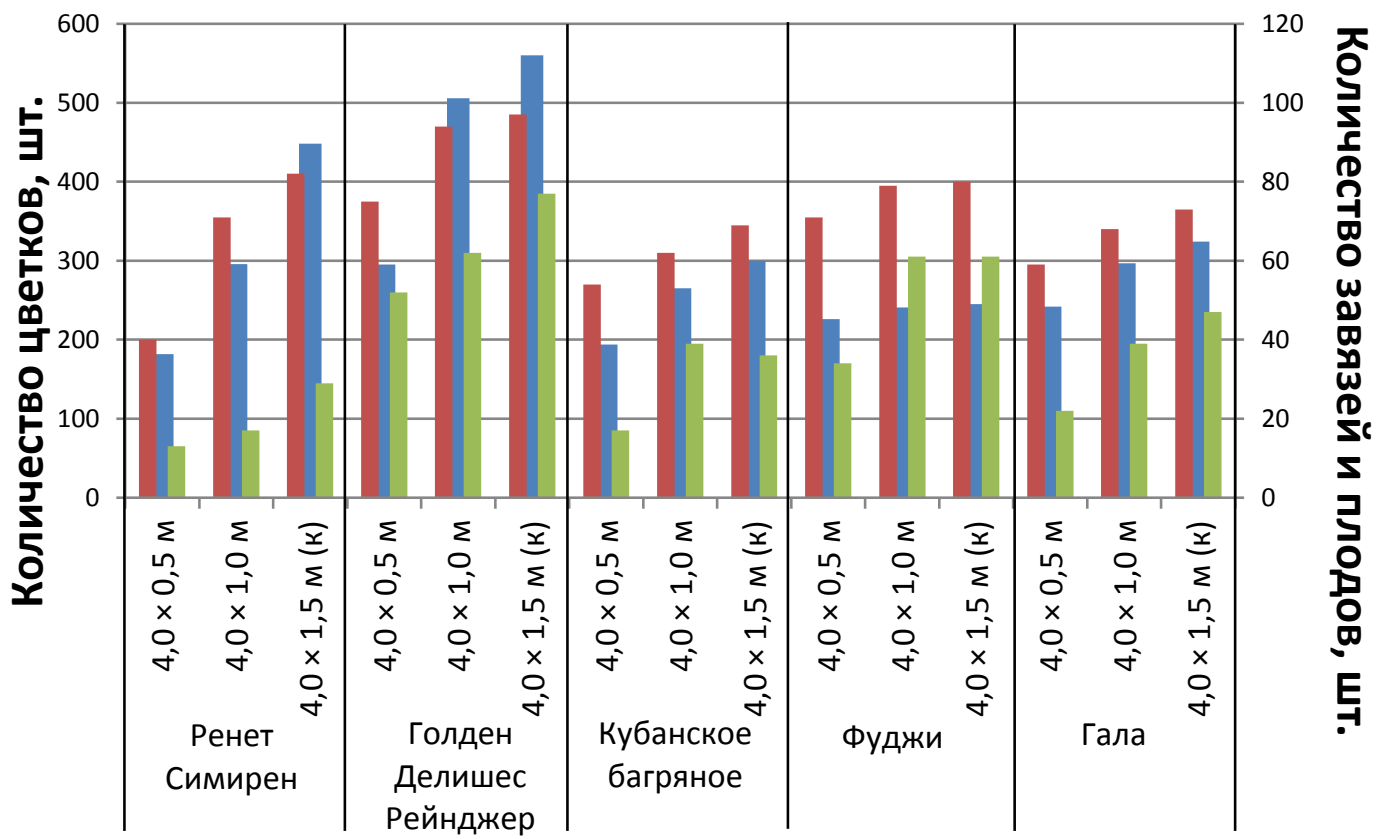

шветки, шт./дер. Полезная завязь, шт./дер. Плоды, шт./дер.

a

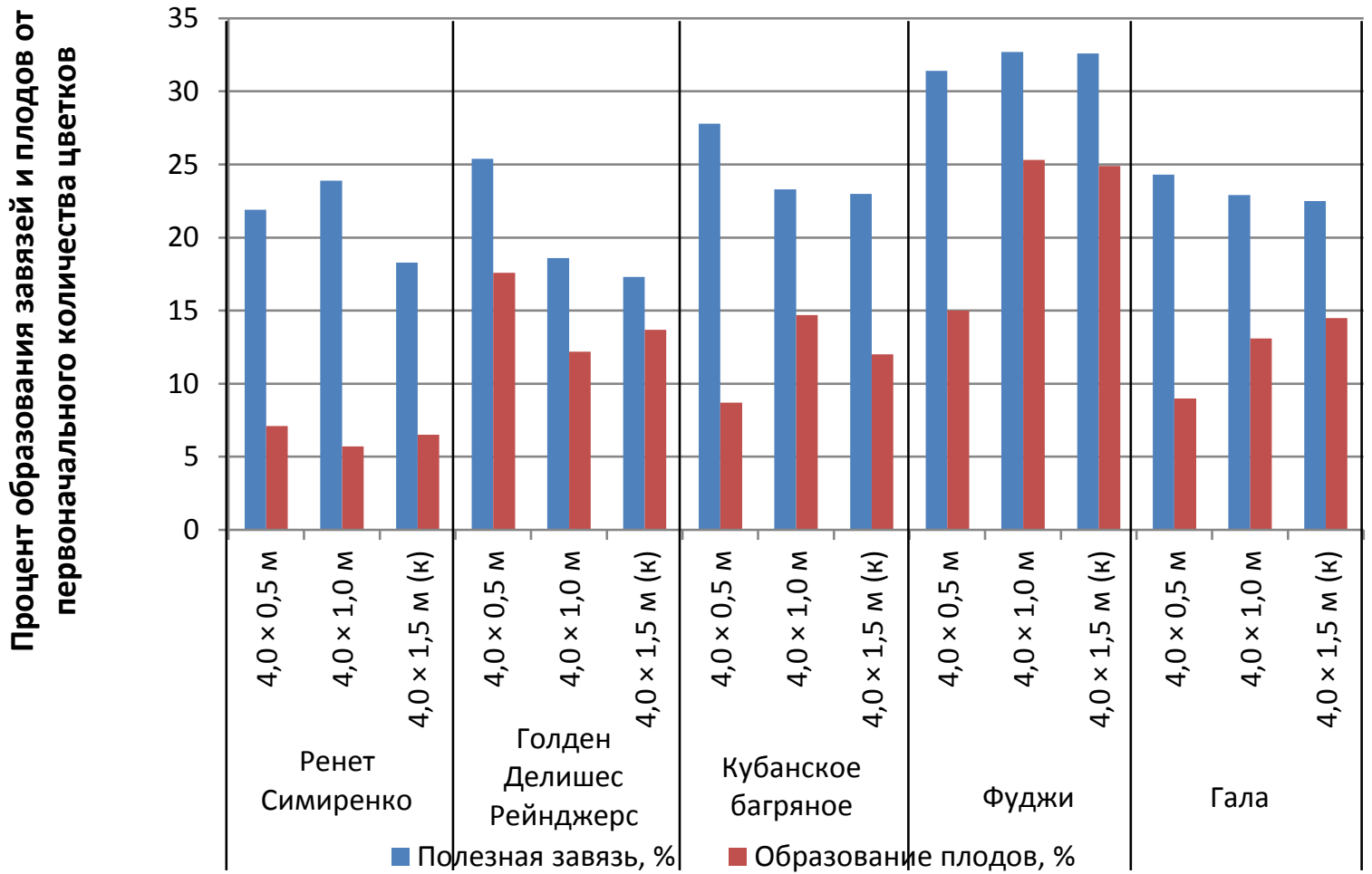

6

Рис. 3. Влияние схемы размещения растений на особенности формирования генеративных органов яблони (цветков, завязей и плодов), 2019 г.: а - количественные показатели; б - процентное соотношение 
Наибольший процент сформировавшихся плодов от первоначального количества цветков $(7,1 \%)$ зарегистрирован при схеме посадки 4,0 $\times 0,5$ м. При схеме посадки 4,0 × 0,5 м на сорте Голден Делишес Рейнджерс зафиксированы максимальные доли полезной завязи и сформировавшихся плодов - на 46,8 и 28,5 \% больше контрольного варианта соответственно.

Большие доли полезной завязи и сформировавшихся плодов по сравнению с контролем отмечены у растений сорта Кубанское багряное при схеме посадки 4,0 × 1,0 м, у растений сорта Фуджи - при 4,0 × 1,0 м, $4,0 \times 1,5$ м. У яблони сорта Гала при схеме посадки 4,0 × 0,5 м отмечена максимальная доля полезной завязи, а при схеме посадки 4,0 × 1,5 м - максимальный процент сформировавшихся плодов.

Дальнейшие наблюдения за процессом формирования плодов показали, что наиболее интенсивное увеличение данного параметра отмечено уже в первые три недели после цветения до образования предзародыша в семенах. В дальнейшем интенсивность роста плодов постепенно снижалась. Как видно из рисунка 4, уплотнение насаждений не оказало негативного влияния на формирование размеров плодов.
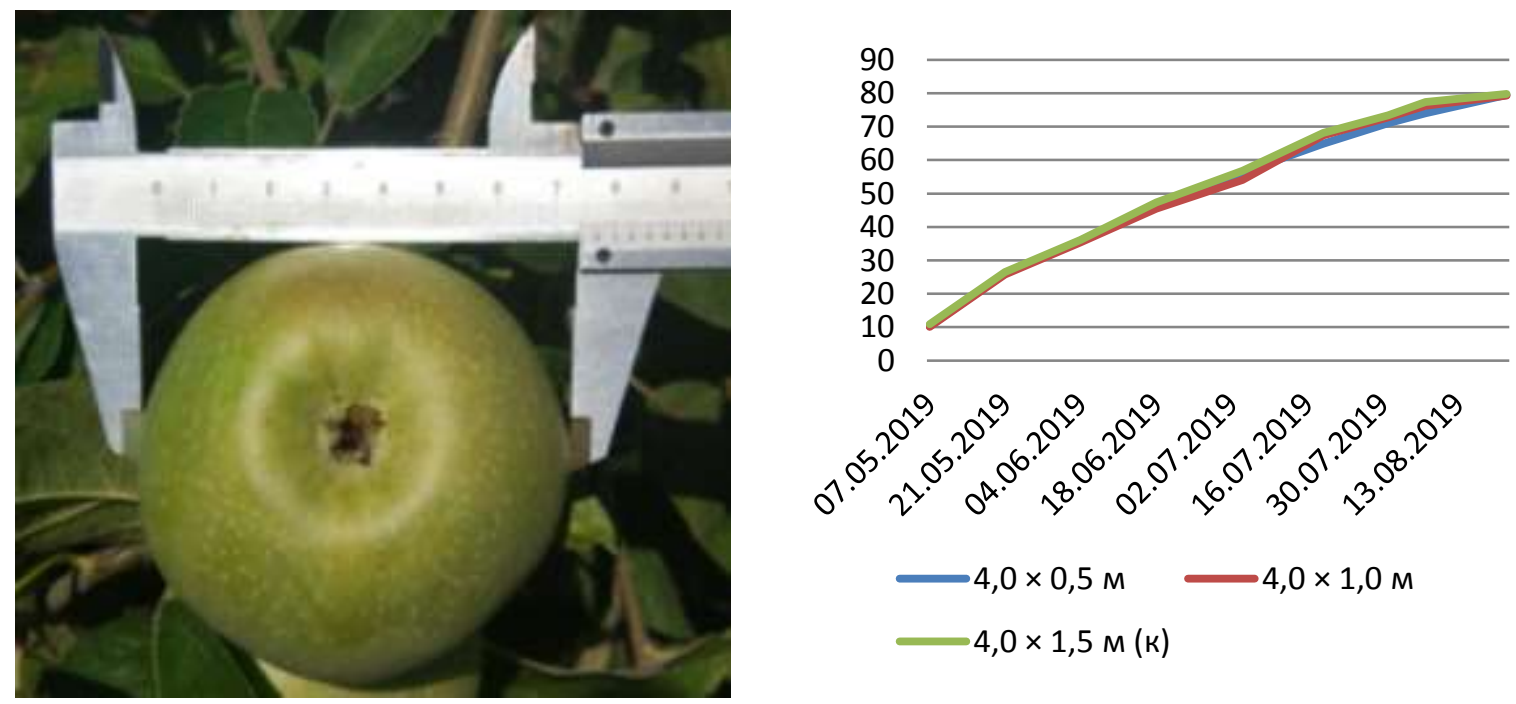

Рис. 4. Динамика роста плодов яблони сорта Ренет Симиренко, 2019 г. 
Известно, что уплотнение насаждений ускоряет наступление периода товарного плодоношения $[7,8]$. Кроме того, на данный показатель оказывает большое влияние сорт. Так, во время вегетации 2019 года, на третий год после закладки сада, отмечено наступление периода товарного плодоношения яблоневых насаждений.

В опытных насаждениях сортов Ренет Симиренко и Голден Делишес Рейнджерс (схемы посадки 4,0 × 0,5 м; 4,0 × 1,0 м) урожай (кг/дер.) характеризовался минимальными значениями (ниже контрольных значений на $16,5-57,7$ \%). Наименьший урожай (кг/дер.) растений сортов Кубанское багряное, Фуджи, Гала также отмечен при схеме посадки 4,0 × 0,5 м - ниже контрольных показателей на 5,0-36,4 \%. Вместе с тем, данный показатель достигал максимальных значений при использовании схемы посадки 4,0 × 1,0 м - выше значений контроля на 2,0-90,8 \% (рис. 5a).

При оценке продуктивности растений сортов Ренет Симиренко, Голден Делишес Рейнджерс, Кубанское багряное, Гала с единицы площади (1 га) установлено, что данный показатель был максимален при схеме посадки 4,0 × 0,5 м - разница с контролем составила 27,2-140,0\%. Однако следует отметить, что урожайность растений яблони сорта Ренет Симиренко при схеме размещения 4,0 × 1,0 м незначительно отличалась от варианта с более плотным размещением деревьев (рис. 5б). Растения сорта Фуджи показали наибольшую продуктивность при размещении по более плотным схемам посадки, урожайность по двум вариантам опыта $(4,0 \times 0,5 ; 4,0 \times 1,0)$ составила 28,3 т/га - на 185,0 \% выше контрольных значений (рис. 5б).

Также в ходе эксперимента установлено, что несмотря на увеличение продуктивности деревьев при схеме посадки 4,0 × 0,5 м, средняя масса плодов не уменьшалась или уменьшалась незначительно относительно контроля и составила в среднем 150-246 г в зависимости от сорта (табл.). 
Плодоводство и виноградарство Юга России № 69(3), 2021 г.

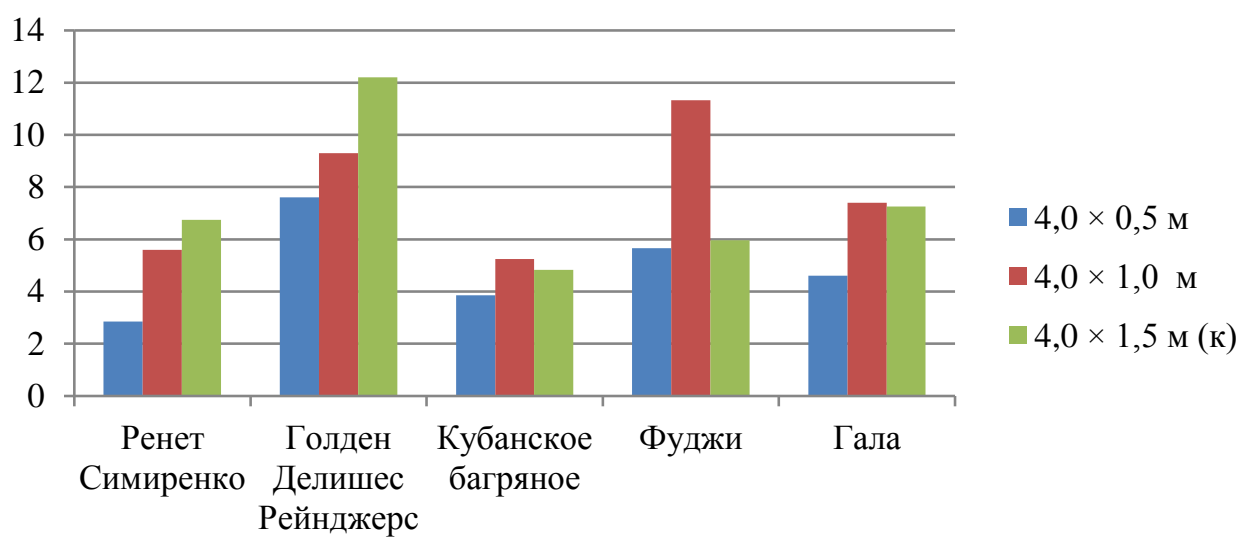

a

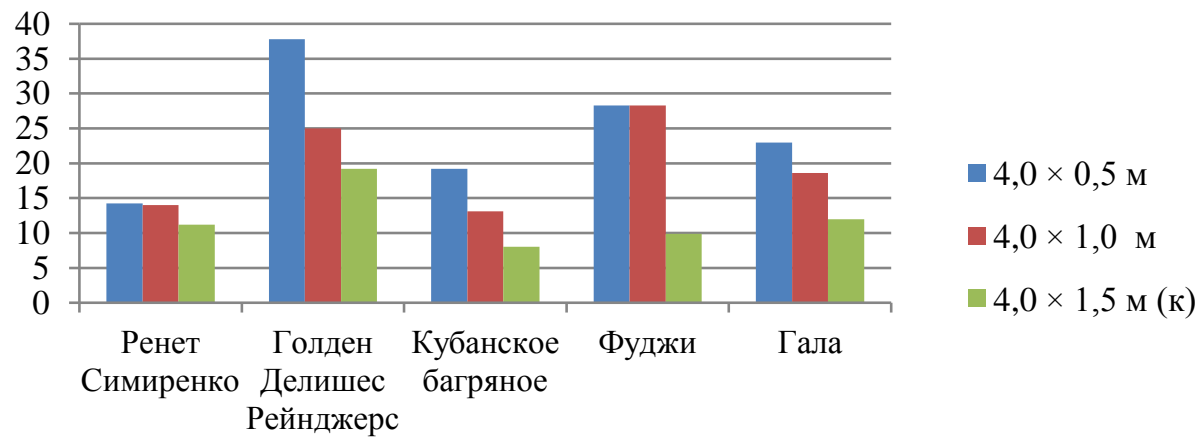

б

Рис. 5. Влияние схем размещения растений на хозяйственную продуктивность (хозяйственный урожай) растений яблони различных сортов:

$\mathrm{a}-$ хозяйственный урожай, кг/дерево; б - хозяйственная продуктивность, т/га.

Особенности формирования товарного качества плодов под влиянием схем посадки, учхоз «Кубань», 2019 г.

\begin{tabular}{|c|c|c|c|c|c|c|c|}
\hline \multirow[b]{2}{*}{ Сорт } & \multirow[b]{2}{*}{ Вариант } & \multirow{2}{*}{$\begin{array}{c}\text { Средняя масса } \\
\text { плода, кг }\end{array}$} & \multicolumn{4}{|c|}{ Выход товарных плодов, \% } & \multirow{2}{*}{$\begin{array}{c}\text { Caxap, } \\
\%\end{array}$} \\
\hline & & & высший & первый & второй & третий & \\
\hline \multirow{3}{*}{$\begin{array}{l}\text { Ренет } \\
\text { Симиренко }\end{array}$} & $4,0 \times 0,5$ & 0,193 & 100,0 & - & - & - & 12,3 \\
\hline & $4,0 \times 1,0$ & 0,230 & 100,0 & - & - & - & 13,4 \\
\hline & $4,0 \times 1,5(\kappa)$ & 0,230 & 100,0 & - & - & - & 13,9 \\
\hline \multirow{3}{*}{$\begin{array}{l}\text { Голден } \\
\text { Делишес } \\
\text { Рейнджерс }\end{array}$} & $4,0 \times 0,5$ & 0,160 & 92,0 & 4,0 & 4,0 & - & 13,5 \\
\hline & $4,0 \times 1,0$ & 0,155 & 86,0 & 11,0 & 3,0 & - & 14,2 \\
\hline & $4,0 \times 1,5$ (к) & 0,145 & 74,0 & 19,0 & 7,0 & - & 13,0 \\
\hline \multirow{3}{*}{$\begin{array}{l}\text { Кубанское } \\
\text { багряное }\end{array}$} & $4,0 \times 0,5$ & 0,246 & 99,0 & 1.0 & - & - & 11,2 \\
\hline & $4,0 \times 1,0$ & 0,25 & 97,0 & 3,0 & - & - & 11,5 \\
\hline & $4,0 \times 1,5(\kappa)$ & 0,32 & 100 & - & - & - & 11,0 \\
\hline \multirow[t]{3}{*}{ Фуджи } & $4,0 \times 0,5$ & 0,182 & 94,0 & 3,0 & - & 3,0 & 15,5 \\
\hline & $4,0 \times 1,0$ & 0,17 & 90,0 & 10,0 & - & - & 14,8 \\
\hline & $4,0 \times 1,5$ (к) & 0,173 & 92,0 & 6,0 & - & 2,0 & 14,3 \\
\hline \multirow[t]{3}{*}{ Гала } & $4,0 \times 0,5$ & 0,15 & 90,0 & 7,0 & 3,0 & - & 11,7 \\
\hline & $4,0 \times 1,0$ & 0,145 & 95,0 & 3,0 & 2,0 & - & 11,0 \\
\hline & $4,0 \times 1,5(\kappa)$ & 0,155 & 87,0 & 5,0 & 8,0 & - & 12,0 \\
\hline
\end{tabular}


Плодоводство и виноградарство Юга России № 69(3), 2021 г.

Химический состав плодов определяет их вкус и питательную ценность. По результатам исследований, не отмечено очевидного влияния схем посадки на содержание сахара в плодах растений яблони.

Bbыводы. Таким образом, период товарного плодоношения растений всех изучаемых сортов яблони наступил на третий год после закладки сада. При этом уже в первый год товарного плодоношения отмечено влияние схем размещения на реализацию генеративной функции растений яблони.

Показано, что уплотненное размещение деревьев оказывает положительное влияние на процессы закладки и дифференциации генеративных почек у растений яблони всех изучаемых сортов - при наиболее плотной схеме посадки отмечены более раннее наступление 3-го этапа органогенеза генеративных почек растений (на примере сорта Голден Делишес Рейнджерс), а также максимальные показатели закладки генеративных почек.

Наибольшее количество полезных завязей и урожай (кг/дер.) фиксировались в вариантах со схемами размещения деревьев 4,0 × 1,0 м и 4,0 × 1,5 м (контроль). Однако с увеличением плотности посадки наблюдалось повышение хозяйственной продуктивности насаждений, так как невысокие урожаи с одного растения компенсировались большим количеством растений на единицу площади, без потерь в товарном качестве плодов.

\section{Литература}

1. Чумаков С.С. Продукционный процесс плодовых растений и пути его регуляции в условиях Западного Предкавказья : автореф. дис. ... д-ра с.-х. наук : 03.01 .05 / Чумаков Сергей Семёнович. Краснодар, 2013. 41 с.

2. Дорошенко Т.Н., Захарчук Н.В., Рязанова Л.Г. Адаптивный потенциал плодовых растений юга России. Краснодар: Просвещение-Юг, 2010. 123 с.

3. D'Abrosca B., Scognamiglio M., Corrado L., Chiocchio I., Zampella L., Mastrobuoni F., Rega P., Scortichini M., Fiorentino A., Petriccione M. Evaluation of different training systems on Annurca apple fruits revealed by agronomical, qualitative and NMR-based metabolomic approaches // Food chemistry. 2017. Vol. 222. pp. 18-27. doi: 10.1016/j.foodchem.2016.11.144.

4. Беляева, А.В., Парубок Р.П., Афифа Т., Чумаков С.С. Особенности возделывания плодовых культур по интенсивным технологиям в условиях Краснодарского края // Агроэкологические аспекты устойчивого развития АПК: материалы XV Международной научной конференции (Брянск, 09-10 апреля 2018 г.). Брянск, 2018. С. 372-375. 
5. Егоров Е.А., Шадрина Ж.А., Кочьян Г.А. Современные новации, обеспечивающие стабильность плодоводства [Электронный ресурс] // Плодоводство и виноградарство Юга России. 2012. № 17(5). С. 117-126. URL: https://journalkubansad.ru/ pdf/12/05/15.pdf (дата обращения: 01.03.2021).

6. Маринин М.С. Подбор и оценка конструкций интенсивных насаждений яблони в условиях предгорной плодовой зоны Краснодарского края : дис. ... канд. с.-х. наук : 06.01.08 / Маринин Максим Сергеевич. Краснодар, 2013. 126 с.

7. Сазонов, Ф.Ф., Евдокименко С.Н., Кулагина В.Л. Адаптивные технологии выращивания плодово-ягодных культур. Брянск: Изд-во Брянской ГСХА, 2012. 54 с.

8. Badiu D., Arion F.H., Muresan I.C., Lile R., Mitre V. Evaluation of economic efficiency of apple orchard investments // Sustainability. 2015. Vol. 7. № 8. C. 10521-10533. doi: 10.3390/su70810521.

9. Autio W., Robinson T.L., Black B., Crassweller R., Fallahi E., Parker M., Quezada R.P., Wolfe D. Budagovsky, Geneva, Pillnitz, and Malling apple rootstocks affect «Honeycrisp» performance over the first five years of the 2010 NC-140 «Honeycrisp» Apple Rootstock Trial // J. Amer. Pomol. Soc. 2017. Vol. 71. №. 3. pp. 149-166.

10. Fallahi E., Kiester M.J., Fallahi B., Mahdavi S. Rootstock, canopy architecture, bark girdling, and scoring influence on growth, productivity, and fruit quality at harvest in «Aztec Fuji» apple // HortScience. 2018. Vol. 53. №. 11. pp. 1629-1633. doi: 10.21273/ HORTSCI13348-18.

11. Lordan J., Gomez M., Francescatto P., Robinson T.L. Long-term effects of tree density and tree shape on apple orchard performance, a 20 year study-part 2, economic analysis // Scientia Horticulturae. 2019. Vol. 244. pp. 435-444. doi: 10.1016/j.scienta.2018.03.031.

12. Ozkan Y., Yıldız K., Küçüker E., Çekiç Ç., Özgen M., Akça Y. Early performance of cv. Jonagold apple on M. 9 in five tree training systems // Horticultural Science. 2012. Vol. 39. №. 4. pp. 158-163. doi: 10.17221/35/2012-HORTSCI.

13. Sagong D.H., Yoon T.M. Optimum crop load in different planting densities of adult «Fuji»/M. 9 apple tree for preventing biennial bearing and stabilizing tree vigor // Horticultural Science \& Technology. 2015. Vol. 33. №. 1. pp. 1-10. doi: 10.7235/hort.2015.13126.

14. Gandev S., Nanev I., Savov P.R., Isuf E., Kornov G., Serbezova D. The effect of three training systems on the vegetative and reproductive habits of the apple cultivar «Braeburn» grafted on M9 rootstock // Bulgarian Journal of Agricultural Science. 2016. Vol. 22. №. 4. pp. 600-603.

15. Hampson C.R., Quamme H.A., Kappel F., Brownlee R.T. Varying density with constant rectangularity: II. Effects on apple tree yield, fruit size, and fruit color development in three training systems over ten years // HortScience. 2004. Vol. 39. №. 3. pp. 507-511. doi: 10.21273/HORTSCI.39.3.507.

16. Reig G., Lordan J., Miranda Sazo M., Hoying S., Fargione M., Reginato G., Donahue D.J., Francescatto P., Fazio G., Robinson T. Long-term performance of «Gala», «Fuji» and «Honeycrisp» apple trees grafted on Geneva rootstocks and trained to four production systems under New York State climatic conditions // Scientia Horticulturae. 2019. Vol. 244. pp. 277-293. doi: 10.1016/j.scienta.2018.09.025.

17. Robinson T. L. Performance of pear and quince rootstocks with three cultivars in four high density training systems in the northeastern United States // Acta Horticulturae. 2008. Vol. 800. pp. 793-802. doi: 10.17660/ActaHortic.2008.800.108

18. Šabajevienė G. Uselis N., Samuolienė G., Kviklys D., Sakalauskaitė J., Duchovskis P. Orchard planting density effect on physiological indexes of apple trees «Auksis» on P 22 rootstock // Zemdirbyste-Agriculture. 2009. Vol. 96 (3). pp. 83-92. 
19. Программа и методика сортоизучения плодовых, ягодных и орехоплодных культур / под общ. ред. Е.Н. Седова, Т.П. Огольцовой. Орел: ВНИИСПК, 1999. 608 с.

20. Киселева Г.К. Метод анатомо-морфологической оценки адаптивного и продуктивного потенциала сортов плодовых культур винограда // Современные методология, инструментарий оценки и отбора селекционного материала садовых культур и винограда. Краснодар, 2017. С. 51-60.

21. Григорьева Л.В. Агробиологические аспекты повышения продуктивности яблони в насаждениях ЦЧР РФ: дис. ... д-ра с.-х. наук: 06.01.08 / Григорьева Людмила Викторовна. Мичуринск, 2015. 426 с.

22. Исаева И.С. Органогенез плодовых растений. М.: МГУ им. М.В. Ломоносова, 1977. $33 \mathrm{c}$.

23. Усков А.И. Органогенез яблони. М.: «Колос», 1967. 176 с.

\section{References}

1. Chumakov S.S. Produkcionnyj process plodovyh rastenij i puti ego regulyacii v usloviyah Zapadnogo Predkavkaz'ya : avtoref. dis. ... d-ra s.-h. nauk : 03.01 .05 / Chumakov Sergej Semyonovich. Krasnodar, 2013. 41 s.

2. Doroshenko T.N., Zaharchuk N.V., Ryazanova L.G. Adaptivnyj potencial plodovyh rastenij yuga Rossii. Krasnodar: Prosveshchenie-Yug, 2010. $123 \mathrm{s.}$

3. Dl'Abrosca B., Scognamiglio M., Corrado L., Chiocchio I., Zampella L., Mastrobuoni F., Rega P., Scortichini M., Fiorentino A., Petriccione M. Evaluation of different training systems on Annurca apple fruits revealed by agronomical, qualitative and NMR-based metabolomic approaches // Food chemistry. 2017. Vol. 222. pp. 18-27. doi: 10.1016/j.foodchem.2016.11.144.

4. Belyaeva, A.V., Parubok R.P., Afifa T., Chumakov S.S. Osobennosti vozdelyvaniya plodovyh kul'tur po intensivnym tekhnologiyam v usloviyah Krasnodarskogo kraya // Agroekologicheskie aspekty ustojchivogo razvitiya APK: materialy XV Mezhdunarodnoj nauchnoj konferencii (Bryansk, 09-10 aprelya 2018 g.). Bryansk, 2018. S. 372-375.

5. Egorov E.A., Shadrina Zh.A., Koch'yan G.A. Sovremennye novacii, obespechivayushchie stabil'nost' plodovodstva [Elektronnyj resurs] // Plodovodstvo i vinogradarstvo Yuga Rossii. 2012. № 17(5). S. 117-126. URL: https://journalkubansad.ru/pdf/12/05/15.pdf (data obrashcheniya: 01.03.2021).

6. Marinin M.S. Podbor i ocenka konstrukcij intensivnyh nasazhdenij yabloni v usloviyah predgornoj plodovoj zony Krasnodarskogo kraya : dis. ... kand. s.-h. nauk : 06.01.08 / Marinin Maksim Sergeevich. Krasnodar, 2013. 126 s.

7. Sazonov, F.F., Evdokimenko S.N., Kulagina V.L. Adaptivnye tekhnologii vyrashchivaniya plodovo-yagodnyh kul'tur. Bryansk: Izd-vo Bryanskoj GSHA, 2012. 54 s.

8. Badiu D., Arion F.H., Muresan I.C., Lile R., Mitre V. Evaluation of economic efficiency of apple orchard investments // Sustainability. 2015. Vol. 7. № 8. S. 10521-10533. doi: 10.3390/su70810521.

9. Autio W., Robinson T.L., Black B., Crassweller R., Fallahi E., Parker M., Quezada R.P., Wolfe D. Budagovsky, Geneva, Pillnitz, and Malling apple rootstocks affect «Honeycrisp» performance over the first five years of the $2010 \mathrm{NC}-140$ «Honeycrisp» Apple Rootstock Trial // J. Amer. Pomol. Soc. 2017. Vol. 71. №. 3. pp. 149-166.

10. Fallahi E., Kiester M.J., Fallahi B., Mahdavi S. Rootstock, canopy architecture, bark girdling, and scoring influence on growth, productivity, and fruit quality at harvest in «Aztec Fuji» apple // HortScience. 2018. Vol. 53. №. 11. pp. 1629-1633. doi: 10.21273/ HORTSCI13348-18. 
11. Lordan J., Gomez M., Francescatto P., Robinson T.L. Long-term effects of tree density and tree shape on apple orchard performance, a 20 year study-part 2, economic analysis // Scientia Horticulturae. 2019. Vol. 244. pp. 435-444. doi: 10.1016/j.scienta.2018.03.031.

12. Ozkan Y., Yıldız K., Küçüker E., Çekiç Ç., Özgen M., Akça Y. Early performance of cv. Jonagold apple on M. 9 in five tree training systems // Horticultural Science. 2012. Vol. 39. №. 4. pp. 158-163. doi: 10.17221/35/2012-HORTSCI.

13. Sagong D.H., Yoon T.M. Optimum crop load in different planting densities of adult «Fuji»/M. 9 apple tree for preventing biennial bearing and stabilizing tree vigor // Horticultural Science \& Technology. 2015. Vol. 33. №. 1. pp. 1-10. doi: 10.7235/hort.2015.13126.

14. Gandev S., Nanev I., Savov P.R., Isuf E., Kornov G., Serbezova D. The effect of three training systems on the vegetative and reproductive habits of the apple cultivar «Braeburn» grafted on M9 rootstock // Bulgarian Journal of Agricultural Science. 2016. Vol. 22. №. 4. pp. 600-603.

15. Hampson C.R., Quamme H.A., Kappel F., Brownlee R.T. Varying density with constant rectangularity: II. Effects on apple tree yield, fruit size, and fruit color development in three training systems over ten years // HortScience. 2004. Vol. 39. №. 3. pp. 507-511. doi: 10.21273/HORTSCI.39.3.507.

16. Reig G., Lordan J., Miranda Sazo M., Hoying S., Fargione M., Reginato G., Donahue D.J., Francescatto P., Fazio G., Robinson T. Long-term performance of «Gala», «Fuji» and «Honeycrisp» apple trees grafted on Geneva rootstocks and trained to four production systems under New York State climatic conditions // Scientia Horticulturae. 2019. Vol. 244. pp. 277-293. doi: 10.1016/j.scienta.2018.09.025.

17. Robinson T. L. Performance of pear and quince rootstocks with three cultivars in four high density training systems in the northeastern United States // Acta Horticulturae. 2008. Vol. 800. pp. 793-802. doi: 10.17660/ActaHortic.2008.800.108

18. Šabajevienė G. Uselis N., Samuolienė G., Kviklys D., Sakalauskaitė J., Duchovskis P. Orchard planting density effect on physiological indexes of apple trees «Auksis» on P 22 rootstock // Zemdirbyste-Agriculture. 2009. Vol. 96 (3). pp. 83-92.

19. Programma i metodika sortoizucheniya plodovyh, yagodnyh i orekhoplodnyh kul'tur / pod obshch. red. E.N. Sedova, T.P. Ogol'covoj. Orel: VNIISPK, 1999. 608 s.

20. Kiseleva G.K. Metod anatomo-morfologicheskoj ocenki adap tivnogo i produktivnogo potenciala sortov plodovyh kul'tur vinograda // Sovremennye metodologiya, instrumentarij ocenki i otbora selekcionnogo materiala sadovyh kul'tur i vinograda. Krasnodar, 2017. S. 51-60.

21. Grigor'eva L.V. Agrobiologicheskie aspekty povysheniya produktivnosti yabloni v nasazhdeniyah CChR RF: dis. ... d-ra s.-h. nauk: 06.01.08 / Grigor'eva Lyudmila Viktorovna. Michurinsk, 2015. $426 \mathrm{~s}$.

22. Isaeva I.S. Organogenez plodovyh rastenij. M.: MGU im. M.V. Lomonosova, 1977. $33 \mathrm{~s}$.

23. Uskov A.I. Organogenez yabloni. M.: Kolos, 1967. 176 s. 